\title{
Carbamazepine in Treatment of the Violent Psychotic Patient
}

Lauren A. Pate, MD

Baylor College of Medicine, Houston Texas

Follow this and additional works at: https://jdc.jefferson.edu/jeffjpsychiatry

Part of the Psychiatry Commons

Let us know how access to this document benefits you

\section{Recommended Citation}

Pate, MD, Lauren A. (1986) "Carbamazepine in Treatment of the Violent Psychotic Patient," Jefferson Journal of Psychiatry. Vol. 4 : Iss. 1 , Article 7.

DOI: https://doi.org/10.29046/JJP.004.1.004

Available at: https://jdc.jefferson.edu/jeffjpsychiatry/vol4/iss1/7

This Article is brought to you for free and open access by the Jefferson Digital Commons. The Jefferson Digital Commons is a service of Thomas Jefferson University's Center for Teaching and Learning (CTL). The Commons is a showcase for Jefferson books and journals, peer-reviewed scholarly publications, unique historical collections from the University archives, and teaching tools. The Jefferson Digital Commons allows researchers and interested readers anywhere in the world to learn about and keep up to date with Jefferson scholarship. This article has been accepted for inclusion in Jefferson Journal of Psychiatry by an authorized administrator of the Jefferson Digital Commons. For more information, please contact: JeffersonDigitalCommons@jefferson.edu. 


\title{
Carbamazepine in Treatment of the Violent Psychotic Patient
}

\author{
Lauren A. Pate, M.D.
}

Violence in the psychiatric setting may be perpetrated by patients with a variety of diagnoses including character disorders, episodic dyscontrol syndromes, and drug or alcohol intoxication. The violent behavior of aggressive psychotic patients is typically the most bizarre, unpredictable, and the least responsive to intervention with neuroleptics or lithium carbonate. Carbamazepine, an established anticonvulsant, has achieved growing prominence as an adjunctive measure in treatment of the violent psychotic. This paper will review the literature and summarize the posited pharmacological mechanisms, reported side effects, and clinical experience with carbamazepine in controlling the symptoms of violence and aggression in psychosis.

Anticonvulsants were first used in the treatment of aggressive psychotic patients in 1943 (1). Carbamazepine, introduced in 1963 as an anticonvulsant particularly effective in temporal lobe epilepsy, has been reported to be useful in treating aggression associated with psychosis in patients with bipolar affective disorder, schizoaffective disorder, and schizophrenia with and without EEG abnormalities. The first successful open clinical trials in patients with bipolar disorder were conducted in Japan in the early 1970's. Two groups of investigators demonstrated anti-manic and slight anti-depressive effects in $75 \%$ (2) and $55 \%$, respectively, of their patients with bipolar affective disorder, and prophylactic effects in both manic (71\%) and depressive $(64 \%)$ episodes $(3,4)$, although some patients received combinations of carbamazepine and lithium and/or other drugs.

A series of double-blind controlled trials followed these studies. Okuma et al. compared chlorpromazine and carbamazepine and reported equivalent anti-manic effects (5). Ballenger and Post conducted double-blind, placebocontrolled trials of carbamazepine in nine manic patients, seven of whom had partial to marked therapeutic responses (6); an additional patient who had been unresponsive to lithium and other anticonvulsants also improved on carbamazepine (7). Subsequent published cases and open studies reported the efficacy of carbamazepine combined with lithium carbonate (8-15), particularly in patients in whom lithium was less effective or who experienced a continuous circular or a rapidly cycling course. Post et al. also provided case reports which suggest that carbamazepine may have prophylactic effects (16). Okuma et al. conducted a

Dr. Pate is a third-year resident at Baylor College of Medicine, Houston, Texas. 
double-blind controlled trial showing prophylactic effects of carbamazepine in $60 \%$ and placebo in $22.2 \%$ of their patients (U-test, $\mathrm{p}<0.10)(17)$. Kishimoto et al. found some prophylactic effects of carbamazepine in manic and depressive episodes in $75 \%$ of their thirty-two cases, all followed for at least seven years; the effects being significantly greater in the group with onset of illness before age 20 ( $p<0.01$, Fisher's exact test) (18). A double-blind controlled study comparing carbamazepine plus haloperidol and placebo plus haloperidol in lithium carbonate- and neuroleptic-resistant patients with "excited psychoses" found a significant improvement of symptoms including "hostility" and "excitement" in the treatment group over the placebo group $(\mathrm{p}<.03)$, although both groups improved (19).

There are also reports of patients with schizoaffective disorder who responded to carbamazepine. Folks, King et al. observed improvement in two of three such patients given carbamazepine (14). Brooks and Lessin reported the successful carbamazepine treatment of a man with schizoaffective disorder and resistant lithium-induced nephrogenic diabetes insipidus (20). Kraft, Hassenfeld, and Zarr published the case of a previously treatment-refractory patient whose auditory hallucinations responded to carbamazepine (21). Despite encouraging case reports, to date there has been no controlled trial of carbamazepine in schizoaffective disorder.

Carbamazepine has been prescribed for schizophrenics with and without abnormal EEG's in whom violent behavior was particularly problematic. In an open trial, Hakola and Laulumaa treated eight schizophrenics with combinations of carbamazepine and neuroleptics. The eight patients all showed EEG abnormalities but had not been diagnosed as epileptic. Following the combination treatment, all eight patients showed decreased aggressive behavior, and four of the eight showed diminished symptoms of schizophrenia as well (22). Luchins had similar results in six schizophrenics with normal EEG's (23), and Yassa and Dupont reported a similarly-responsive case (24). Neppe conducted a double-blind, randomized study of carbamazepine in eleven chronic schizophrenics with EEG abnormalities, eight of whom improved while on carbamazepine ( $p=.03$, Wilcoxon; $p<.005$, ANOVA) (25). In contrast, Stevens and Bigelow et al. reported two cases of psychosis aggravated by therapeutic doses of carbamazepine (26). In summary, the available literature suggests that carbamazepine may be a useful adjunctive measure in the treatment of aggressive or violent psychotic patients, some of whom may have EEG abnormalities. Carbamazepine's apparent effect on both aggressive behavior and psychotic symptoms raises questions about the compound's mechanism of action. The only anticonvulsant with a tricyclic structure, carbamazepine is a polycyclic drug whose steric structure resembles that of chlorpromazine, imipramine, and maprotiline. Because its three rings lie in a plane different from that of the amide group, it resembles other anticonvulsants as well (27). Carbamazepine is classified as a neutral lipophilic substance, which enables the molecule to pass easily through lipid membranes and facilitates its transport into the central nervous system. 
Two different metabolic pathways are discernible: epoxidation of position 10,11 by hepatic monooxygenases, and hydroxylation in one of the aromatic rings by hepatic oxygenases. Both metabolites undergo subsequent glucuronide formation. The epoxidation pathway is quantitatively the more important one, and there is speculation that 10,11-epoxycarbamazepine contributes to the drug's antiepileptic (and possible anti-aggressive) activity (28). There is also evidence which suggests that carbamazepine induces certain enzymes, e.g., cytochrome P-450 and epoxide hydrase, and may hasten its own degradation. The measured half-life after a single dose (37 hours) is significantly greater than the half-life after repeated doses (28 hours) in multiple trials (28).

Animal studies initially demonstrated carbamazepine's anticonvulsive effects and located its site of action in the limbic region of the brain. Carbamazepine's anti-epileptic properties were most evident in electrically-induced seizures in rats and mice, and somewhat less pronounced in chemically induced seizures in these animals. Hypothalamically-induced rage in cats was also controlled by carbamazepine, suggesting effectiveness in specific types of aggression. In the cat epilepsy model, electrical stimulation of various limbic structures produced after-discharges recorded in the stimulated structures themselves and interrelated areas. The hippocampal after-discharge, possibly involved in psychomotor epilepsy and a particularly useful measure of anticonvulsant efficacy, was shortened by carbamazepine at a dose of $3 \mathrm{mg} / \mathrm{kg}$ in cats. The drug had no effect on the Purkinje cells of the cerebellar cortex, suggesting that the mode of anticonvulsant action of carbamazepine differs from that of diphenylhydantoin and diazepam (29). Studies of the fighting behavior of mice suggest that carbamazepine in high doses has general anti-aggressive and anxiolytic effects. Antiparkinsonian and anticholinergic properties also appear only at very high doses. Contrary to clinical reports in humans, traditional reserpine and amphetamine antagonism trials in animals have not demonstrated antidepressant or antipsychotic effects. for carbamazepine. To measure carbamazepine's possible anti-depressant activity, $1,000 \mathrm{mg} / \mathrm{kg}$ of the drug was administered to rodents with reserpine-induced ptosis but produced no antagonistic effect. Similarly, to test for neuroleptic properties, $300 \mathrm{mg} / \mathrm{kg}$ of carbamazepine was given to rats with amphetamine-induced stereotypy, again without antagonism (29). These findings have led investigators to focus on the limbic system-temporal lobe area as the primary site of carbamazepine's action and to attempt to identify possible neurochemical explanations for its psychotropic efficacy.

Postulating an association between the high density of opiate receptors in the limbic system and carbamazepine's mechanism of action, Post et al. measured opioid activity in patients with affective disorders treated with carbamazepine. They reported that the drug exerted no significant effect on cerebral spinal fluid (CSF) opioid activity (30), and found no significant association between CSF GABA levels and carbamazepine dose or blood level of the drug (31). They subsequently examined the effects of carbamazepine on receptors of various major neurotransmitters and other substances. Data sug- 
gested that, unlike neuroleptics, carbamazepine does not block dopamine receptors. It did not produce parkinsonian symptoms, tardive dyskinesia, or inhibition or suppression of unit firing dopaminergic neurons of the substantia nigra by apomorphine; it did produce minimal elevations of prolactin but did not diminish cocaine- nor amphetamine-induced hyperactivity. Benzodiazepine receptor antagonists did not affect carbamazepine's anticonvulsant activity in amygdaloid seizures, suggesting little effect of carbamazepine at the benzodiazepine receptor as well. Carbamazepine failed to inhibit binding at several receptor sites, including muscarinic-cholinergic $\left({ }^{3} \mathrm{H}-\mathrm{QNB}\right)$, dopamine $\left({ }^{3} \mathrm{H}\right.$-spiroperidol), GABA ( ${ }^{3} \mathrm{H}$-muscimol), imipramine, beta-adrenergic $\left({ }^{3} \mathrm{H}-\mathrm{DHA}\right)$, and opiate ( ${ }^{3} \mathrm{H}$-naloxone) receptors. However, displacement of adenosine analogs was demonstrated, indicating effects on the adenosine receptor, and a blockade of both release and reuptake of norepinephrine, which may be related to carbamazepine's apparent efficacy in bipolar illness (32). Other documented effects of carbamazepine include decreased circulating $\mathrm{T}_{3}$ and $\mathrm{T}_{4}$, efficacy as a vasopressin agonist, increased urinary free cortisol, and decreased CSF somatostatin (32).

Post and his group proposed that carbamazepine, through its anticonvulsant properties, may represent a new class of psychotropic agents for the treatment of affective dysregulation, including aggression as a symptom of a hyperexcited state or limbic seizure (33). This hypothesis was based on Dalby's successful use of carbamazepine in patients with temporal lobe epilepsy and mood disorders (34,35), carbamazepine's inhibition of experimentally induced kindling in the limbic system (particularly amygdaloid seizures), and Post and his coworkers' success in treating affectively disordered patients with carbamazepine. In Post's model, these subcortical seizures, which could manifest as behavioral aberrations such as aggression and psychosis, would not necessarily produce EEG abnormalities; kindling could occur with either environmental or endogenous stimuli (36). Heath's work with deep brain EEG recordings in epileptics and schizophrenics also provides some support for Post's model. Heath describes seizure-like activity in the amygdala, hippocampus, and septal region of epileptics with violent psychotic episodes which closely resembled the spike and slow-wave patterns obtained from the same brain regions in nonepileptic aggressive psychotic patients and psychotic schizophrenics (37).

Although the use of carbamazepine in psychiatric patients is increasing as more data are published, treatment guidelines and side effect profiles have not yet been fully agreed upon. Experimental protocols have suggested administration of carbamazepine in doses ranging from $200 \mathrm{mg} / \mathrm{d}$ to $2,000 \mathrm{mg} / \mathrm{d}$, with most recommending initial doses of $200-400 \mathrm{mg} / \mathrm{d}$ with gradual upward titration to the point of maximum clinical efficacy or dose-limiting side effects (6). Post et al. report treatment with $1,600-2,000 \mathrm{mg} / \mathrm{d}$ with few side effects (38). Blood and CSF levels of the drug have been shown to bear no relationship to clinical response when the drug is used to treat aggressive psychotic psychiatric patients, although CSF levels of carbamazepine-10,11-epoxide correlated 
significantly with clinical response when measured after a month of treatment (38). Side effects, however, do appear to be related to the plasma level in some patients, becoming more intolerable when the serum concentration exceeds 9 $\mathrm{ug} / \mathrm{ml}$ (38). The most commonly reported side effects include diplopia, skin rash, fatigue, unsteadiness, transient paresthesias in the extremities, reversible lupus erythematosis syndrome, nystagmus, drowsiness, nausea, vomiting, and neutropenia (39). Though decreases in white blood cell counts are usually clinically insignificant, there have been cases of aplastic anemia (40) and agranulocytosis (41) reported with carbamazepine. Other hematologic effects include thrombocytopenia (42), reticulocytosis (43), and leukocytosis (44). Although the incidence of these blood dyscrasias is low, hematologic monitoring should include a complete blood and platelet count prior to therapy and weekly complete blood counts for the first month, followed by monthly white blood cell counts (40). If leukopenia develops, the dose of the drug should be decreased and the white cell count monitored biweekly. In the event of infection or severe leukopenia (WBC less than $3,000 / \mathrm{mm}^{3}$ or neutrophil count less than $1,500 /$ $\mathrm{mm}^{3}$ ), carbamazepine should be discontinued (41).

There are reports of additional side effects and some drug interactions involving carbamazepine. Because its chemical structure is so closely related to tricyclic antidepressants, carbamazepine may potentiate the action of these drugs when they are used in combination $(39,45)$. Reiss and O'Donnell report two cases of paradoxical carbamazepine-induced mania in children with family histories of affective disorder (46). Fogelson suggests that ataxia, confusion, and vomiting can occur when carbamazepine dosage is increased too abruptly in patients previously unexposed to the drug, as they have lower clearance than those who take it regularly (47). At toxic levels, carbamazepine is also known to produce encephalopathy (39) or schizophrenia-like psychosis (48) in susceptible patients. Kanter et al. described a patient with bipolar disorder who was started on carbamazepine and haloperidol and developed an acute organic brain syndrome with low serum levels of carbamazepine. The syndrome resolved with discontinuation of both medications, and the mania was subsequently controlled on carbamazepine $200 \mathrm{mg}$ b.i.d. alone. The authors suggest that a central nervous system interaction between the two drugs was responsible for the organic symptoms (49). Lithium carbonate-carbamazepine combinations can produce signs of neurotoxicity $(50,51)$, despite therapeutic serum levels of both drugs, and there is one case report of an organic brain syndrome with a lithium carbonate-carbamazepine-haloperidol combination (52). Isoniazid, when given with carbamazepine, produces delirium $(53,54)$. There is one report of neurotoxicity when carbamazepine was combined with metoclopramide (55). Uhde and Post observed significant decreases in serum sodium, choride , and calcium in their patients treated with carbamazepine, but these changes were not correlated with treatment response, although those patients who improved on carbamazepine tended to have greater depression of serum sodium levels. They also suggested that some "nonspecific" side effects may actually be symptoms of 
hyponatremia (56), possibly due to water intoxication, which has also been reported $(57,58)$. Finally, carbamazepine administration has sometimes led to hypothyroidism with and without elevations of thyroid stimulating hormone $(59,32)$, as well as to hepatitis $(60)$.

Although the Food and Drug Administration has not yet approved the use of carbamazepine in refractory violent psychiatric patients, the literature suggests that this compound, used alone or in combination with conventional agents, may be beneficial in the treatment of psychoses associated with bipolar affective disorder, schizoaffective disorder, and schizophrenia. Through its anticonvulsant action or another yet unidentified mechanism, carbamazepine appears to control limbic seizures, which may be related to both psychosis and aggression. Familiarity with potential side effects and drug interactions is necessary as the use of carbamazepine increases. Finally, additional clinical trials are necessary to further assess the safety and spectrum of carbamazepine's efficacy.

\section{REFERENCES}

1. Kalinowsky LB, Putnam TJ: Attempts at treatment of schizophrenia and other nonepileptic psychoses with dilantin. Arch Neurol Psychiatry 49:414-420, 1943

2. Takezaki H, Hanaoka M: The use of carbamazepine in the control of manic depressive psychosis and other manic, depressive states. Clin Psychiat 15:641-648, 1973

3. Okuma T, Kishimoto A, Inoue K, et al: Anti-manic and prophylactic effects of carbamazepine on manic-depressive psychoses. Folia Psychiatr Neurol Jpn 27:283297, 1973

4. Okuma T: Therapeutic and prophylactic effects of carbamazepine in bipolar disorders. Psychiatr Clin North Am 6:157-174, March, 1983

5. Okuma T, Inanaga K, Otsuki S, et al: Comparison of the antimanic efficacy of carbamazepine and chlorpromazine: a double-blind controlled study. Psychopharmacology 66:211-217, 1979

6. Ballenger JC, Post RM: Carbamazepine in manic-depressive illness: a new treatment. Am J Psychiatry 137:782-790, 1980

7. Post RM, Berrettini W, Uhde TW, et al: Selective response to the anticonvulsant carbamazepine in manic-depressive illness: a case study. $J$ Clin Psychopharmacol 4:178-185, 1984

8. Inoue K, Arima S, Tanaka K, et al: A lithium and carbamazepine combination in the treatment of bipolar disorder-a preliminary report. Folia Psychiatr Neurol Jpn 35:465-475, 1981

9. Forrest DV: Bipolar illness after right hemispherectomy: a response to lithium carbonate and carbamazepine. Arch Gen Psychiatry 39:817-819, 1982

10. Lipinski JF, Pope HG: Possible synergistic action between carbamazepine and lithium carbonate in the treatment of three acutely manic patients. Am J Psychiatry 139:948-949, 1982

11. Nolen WA: Carbamazepine, a possible adjunct or alternative to lithium in bipolar disorder. Acta Psychiatr Scand 67:218-225, 1983 
12. Fawcett J, Kravitz HM: The long-term management of bipolar disorders with lithium, carbamazepine, and antidepressants. J Clin Psychiatry 46:58-60, 1985

13. Moss GR, James CR: Carbamazepine and lithium carbonate synergism in mania. Arch Gen Psychiatry 40:588, 1983

14. Folks DG, King LD, Dowdy SB, et al: Carbamazepine treatment of selected affectively disordered inpatients. Am J Psychiatry 139:115-116, 1982

15. Keisling R: Carbamazepine and lithium carbonate in the treatment of refractory affective disorders. Arch Gen Psychiatry 40:223, 1983

16. Post RM, Uhde TW, Ballenger JC, et al: Prophylactic efficacy of carbamazepine in manic-depressive illness. Am J Psychiatry 140:1602-1604, 1983

17. Okuma T, Inanaga $\mathrm{K}$, Otsuki S, et al: A preliminary double-blind study on the efficacy of carbamazepine in prophylaxis of manic-depressive illness. Psychopharmacology 73:95-96, 1981

18. Kishimoto A, Ogura C, Hazama H, et al: Long-term prophylactic effects of carbamazepine in affective disorder. Br J Psychiatry 143:327-331, 1983

19. Klein E, Bental E, Lerer B, et al: Carbamazepine and haloperidol $v$ placebo and haloperidol in excited psychoses: a controlled study. Arch Gen Psychiatry 41:165-170, 1984

20. Brooks SC, Lessin BE: Treatment of resistant lithium-induced nephrogenic diabetes insipidus and schizoaffective psychosis with carbamazepine. Am J Psychiatry 140:1077-1078, 1983

21. Kraft AM, Hassenfeld IN, Zarr M: Response of functional hallucinations to carbamazepine. Am J Psychiatry 141:1018, 1984

22. Hakola HPA, Laulumaa VA: Carbamazepine in treatment of violent schizophrenics. Lancet 1:1358, 1982

23. Luchins DJ: Carbamazepine for the violent psychiatric patient. Lancet 1:766, 1983

24. Yassa R, Dupont D: Carbamazepine in the treatment of aggressive behavior in schizophrenic patients: a case report. Can J Psychiatry 28:566-568, 1983

25. Neppe VM: Carbamazepine as adjunctive treatment in nonepileptic chronic inpatients with EEG temporal lobe abnormalities. J Clin Psychiatry 44:326-331, 1983

26. Stevens JR, Bigelow L, Denney D, et al: Telemetered EEG-EOG during psychotic behaviors of schizophrenia. Arch Gen Psychiatry 36:25 1-262, 1979

27. Gagneux AR: The chemistry of carbamazepine, in Epileptic Seizures-Behavior-Pain Edited by Birkmeyer W. Bern, Hans Huber: 1976

28. Faigle JW, Breckbuhler S, Feldmann KF, et al: The biotransformation of carbamazepine, in Epileptic Seizures-Behavior-Pain Edited by Birkmeyer W. Bern, Hans Huber: 1976

29. Koella WP, Levin P, Baltzer V: The pharmacology of carbamazepine and some other anti-epileptic drugs, in Epileptic Seizures-Behavior-Pain Edited by Birkmeyer W. Bern, Hans Huber: 1976

30. Post RM, Pickar D, Naber D, et al: Effect of carbamazepine on CSF opioid activity: relationship to antidepressant response. Psychiatry Res 5:59-66, 1981

31. Post RM, Ballenger JC, Hare TA, et al: Lack of effect of carbamazepine on gamma-aminobutyric acid in cerebrospinal fluid. Neurology 30:1008-1011, 1980

32. Post RM, Uhde TW, Rubinow DR, et al: Biochemical effects of carbamazepine: relationship to its mechanism of action in affective illness. Prog Neuropsychopharmacol Biol Psychiatry 7:263-271, 1983 
33. Post RM, Uhde TW: Biological relationships between mania and melancholia. Encephale 8:213-228, 1982

34. Dalby MA: Antiepileptic and psychiatric effect of carbamazepine in the treatment of psychomotor epilepsy. Epilepsia 12:325-334, 1971

35. Dalby MA: Behavioral effects of carbamazepine, in Complex Partial Seizures. Advances in Neurology, Vol II. Edited by Penry JK, Daly DD. New York, Raven Press: 331-343, 1975

36. Silberman EK, Post RM: The march of symptoms in a psychotic decompensation. $J$ Nerv Ment Dis 168:104-110, 1980

37. Heath RG: Psychosis and epilepsy: similarities and differences in the anatomicphysiologic substrate, in Temporal Lobe Epilepsy, Mania and Schizophrenia and the Limbic System. Adv Biol Psychiat, Vol 8. Edited by Koella WP, Trimble MR. Karger, Basel: 106-116, 1982

38. Post RM, Uhde TW, Wolff EA: Profile of clinical efficacy and side effects of carbamazepine in psychiatric illness: relationship to blood and CSF levels of carbamazepine and its -10,11-epoxide metabolite. Acta Psychiatr Scand (Suppl) 303:104-120, 1984

39. Tollefson G: Psychiatric implications of anticonvulsant drugs. J Clin Psychiatry 41:295-302, 1980

40. Post RM, Uhde TW: Alternatives to lithium: a focus on carbamazepine, in Affective Disorders Reassessed: 1983. Edited by Ayd FJ, Taylor IT, Taylor BT. Baltimore, Williams and Wilkins: 1983

41. Luchins DJ: Fatal agranulocytosis in a chronic schizophrenic patient treated with carbamazepine. Am J Psychiatry 141:687-688, 1984

42. Baciewicz G, Yerevanian BI: Thrombocytopenia associated with carbamazepine: case report and review. J Clin Psychiatry 45:315-316, 1984

43. Warren JA, Steinbook RM: Case report of carbamazepine-induced reticulocytosis. Am J Psychiatry 140:247-249, 1983

44. Murphy JE, Stewart RB, Springer PK: Carbamazepine-induced leukocytosis. Am J Hosp Pharm 37:550-552, 1980

45. Lesser I: Carbamazepine and desipramine: a toxic reaction. J Clin Psychiatry 45:360, 1984

46. Reiss AL, O'Donnell DJ: Carbamazepine-induced mania in two children: case report. J Clin Psychiatry 45:272-274, 1984

47. Fogelson DL: Using carbamazepine effectively. Am J Psychiatry 141:1130, 1984

48. Franks RD, Richter AJ: Schizophrenia-like psychosis associated with anticonvulsant toxicity. Am J Psychiatry 136:973-974, 1979

49. Kanter GL, Yerevanian BI, Ciccone JR: Case report of a possible interaction between neuroleptics and carbamazepine. Am J Psychiatry 141:1101-1102, 1984

50. Chaudry RP, Waters BGH: Lithium and carbamazepine interaction: possible neurotoxicity. J Clin Psychiatry 44:30-31, 1983

51. Shukla S, Godwin CD, Long LEB, et al: Lithium-carbamazepine neurotoxicity and risk factors. Am J Psychiatry 141:1604-1606, 1984

52. Andrus PF: Lithium and carbamazepine. J Clin Psychiatry 45:525, 1984

53. Wright JM, Stokes EF, Sweeney VP: Isoniazid-induced carbamazepine toxicity and vice versa: a double drug interaction. $N$ Engl J Med 307:1325-1327, 1982

54. Valsalan VC, Cooper GL: Carbamazepine intoxication caused by interaction with isoniazid. $\mathrm{Br}$ Med J 285:261-262, 1982 
55. Sandy KR: Carbamazepine and metoclopromide interaction: possible neurotoxicity. Br Med J 288:830, 1984

56. Uhde TW, Post RM: Effects of carbamazepine on serum electrolytes: clinical and theoretical implications. J Clin Psychopharmacol 3:103-106, 1983

57. Ashton D, Ball SG, Thomas TH, et al: Water intoxication associated with carbamazepine treatment. Br Med J 1:1134-1135, 1977

58. Stephens WB, Espin MLE, Tattersall RB, et al: Water intoxication due to carbamazepine. Br Med J 1:754-755, 1977

59. Aanderud S, Strandjord RE: Hypothyroidism induced by anti-epileptic therapy. Acta Neurol Scand 61:330-332, 1980

60. Zucker P, Daum F, Cohen MI: Fatal carbamazepine hepatitis. J Pediatr 91:667-668, 1977 